\title{
High speed infrared thermography of freezing onion-skin cells
}

\author{
by K. Ikuo ${ }^{1}$, M. Ryu ${ }^{2}$, and J. Morikawa ${ }^{2}$ \\ ${ }^{1}$ Photron Limited, Chiyoda-ku, Tokyo 101-0051, Japan \\ ${ }^{2}$ School of Materials and Chemical Technology, Tokyo Institute of Technology, Tokyo 152-8552, Japan
}

\begin{abstract}
Non-contact quantitative thermal imaging in micro-scale is attractive to realize the non-contact thermal analysis during phase transitions. It visualizes both the temperature field and heat transfer. Here we review the system of IR camera equipped with an original optics and temperature calibration algorithm, which is applicable to achieve the high-quality and fast thermal imaging. The Infrared (IR) optical lens design has been optimized to each wavelength band of the photon type and the thermal type detectors of IR FPA. Typical applications to observe the freezing biological cells are presented. The most recent system enables to visualize the thermal imaging of freezing onionskin cells at 10,000 frames/s during rapid cooling process.
\end{abstract}

\section{Introduction}

The cryopreservation of biological tissues is an indispensable technique in biological engineering. The control of intracellular ice formation or glass formation and dehydration with an extracellular solution are important for cryopreservation, because biological cells are easily damaged by the volume change of ice formation. According to a typical thermodynamic rule, the 1st-order phase transition is accompanied by not only a volume change but also latent heat. Morikawa et al. found that the thermographical imaging was applicable to the thermal analysis of biological cells on the unit cell scale for measuring latent heat release and thermal diffusion during freezing. [1-2] In this study the most recent technique of high-speed infrared camera is applied to analyze the freezing onionskin cells.

\section{Experimental}

\subsection{Subheading (Arial, 9pt, bold)}

To investigate the dynamics of temperature distribution in freezing onionskin cells under cooling was studied by high-speed IR camera as a tool of non-contact thermal imaging for the two-dimensional thermal analysis. A high-speed high-resolution IR camera (640 x 512 matrix of InSb photodetectors) with the normal and the original-designed microscopic lens (magnification $\times 7$ ) were used. The images of the infrared radiation intensity from the top view of the tissues were studied. The images were taken at $1500 \mathrm{~Hz}-10,000 \mathrm{~Hz}$, and the spatial resolution was $4.29 \mu \mathrm{m}-35 \mathrm{~mm}$ per pixel. The detailed measuring conditions are listed in Table 1.

Table 1. Measurement conditions of temperature scan at $250-300 \mathrm{~K}$ (for onionskin cells), and $320-500 \mathrm{~K}$ (for Poly Butylene Terephtalate (PBT).

\begin{tabular}{|l|l|l|}
\hline Temp. scan condition & $250 \mathrm{~K}-300 \mathrm{~K}$ by $5 \mathrm{~K} / \mathrm{s}$ & $320 \mathrm{~K}-500 \mathrm{~K}$ by $2,000 \mathrm{~K} / \mathrm{s}$ \\
\hline Camera type & FLIR X6900sc InSb $3-5 \mu \mathrm{m}$ & FLIR X6900sc InSb $3-5 \mu \mathrm{m}$ \\
\hline Frame rate & $1,500 \mathrm{~Hz} @ 320 \times 256$ & $10,000 \mathrm{~Hz} @ 160 \times 36$ \\
\hline Integration time & $600 \mu \mathrm{s}$ & $80 \mu \mathrm{s}$ \\
\hline Spatial resolution & $35 \mu \mathrm{m}$ & $35 \mu \mathrm{m}$ \\
\hline Angle of view & $11 \mathrm{~mm} \times 9 \mathrm{~mm}$ & $2.6 \mathrm{~mm} \times 1.26 \mathrm{~mm}$ \\
\hline
\end{tabular}

\subsection{Specimens}

Phase change of two different materials were investigated; 1. Onionskin cells on freezing, measuring temperature range was $250 \mathrm{~K}-300 \mathrm{~K}$ controlled by Peltier element cooler , 2. Melting and crystallization of Poly Butylene Terephtalate (PBT) at $320 \mathrm{~K}-500 \mathrm{~K}$. 


\section{Results and analysis}

Figure 1 shows an example of the thermographical image of latent heat of freezing onionskin cells in cooling observed at $1,500 \mathrm{~Hz}$ by InSb IR camera. Temperature rise from each single onionskin cell, separated by a cell-wall, is caused by the $1^{\text {st }}$ order phase transition in cooling. Onionskin cell freezes one time in cooling, even observed by a highspeed at $1,500 \mathrm{~Hz}$, however, he thermal diffusion from outside from the cell influences on the temperature distribution inside the cell. This effect is clearly shown in Fig. 2 where the thermal diffusion effect on temperature are seen as the multiple peaks in one cell.

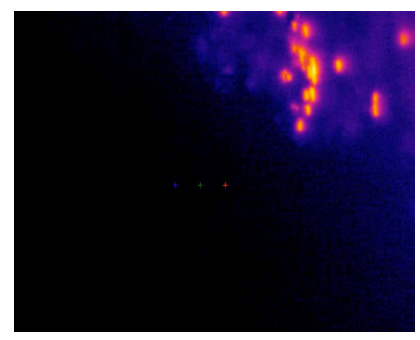

$\mathrm{t}=12 \mathrm{~s}$

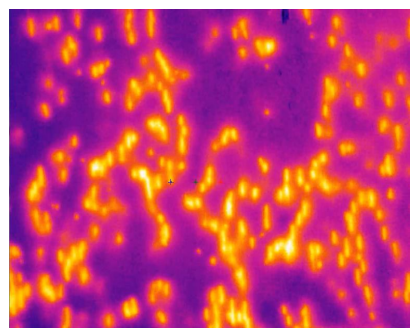

$\mathrm{t}=20 \mathrm{~s}$

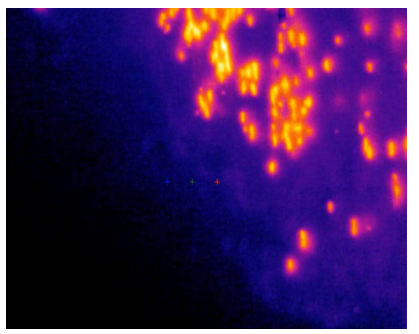

$t=14 \mathrm{~s}$

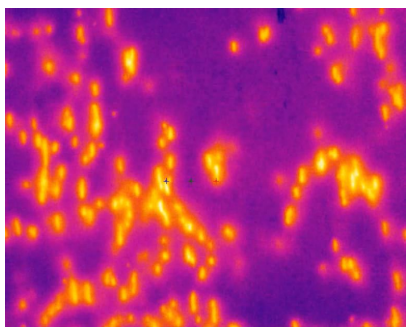

$t=24 \mathrm{~s}$

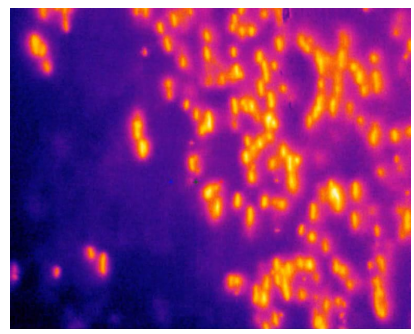

$\mathrm{t}=16 \mathrm{~s}$

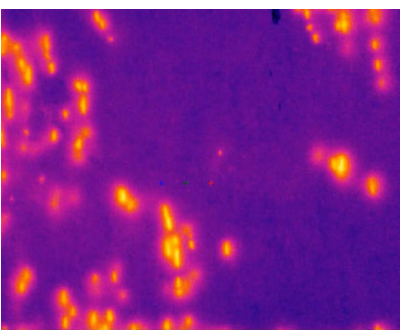

$t=28 s$

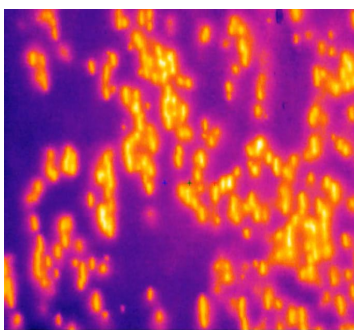

$\mathrm{t}=19 \mathrm{~s}$

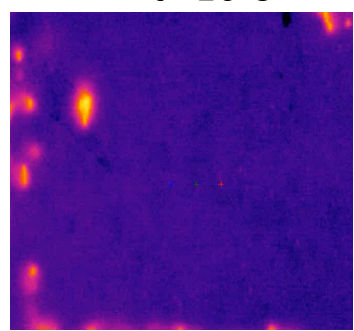

$\mathrm{t}=32 \mathrm{~s}$

Fig. 1: Latent heat of freezing onionskin cells in cooling observed at 1,500 Hz, InSb I camera. Thermal diffusion on the tissues are clearly observed.

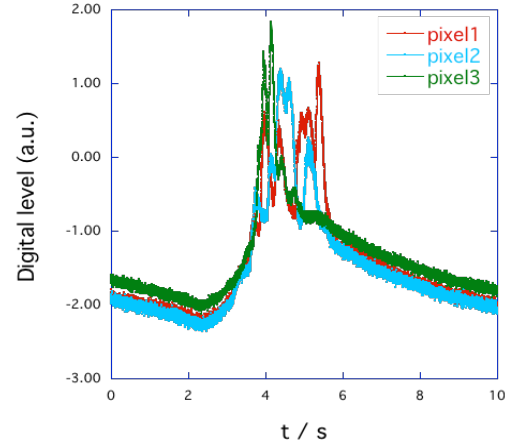

a

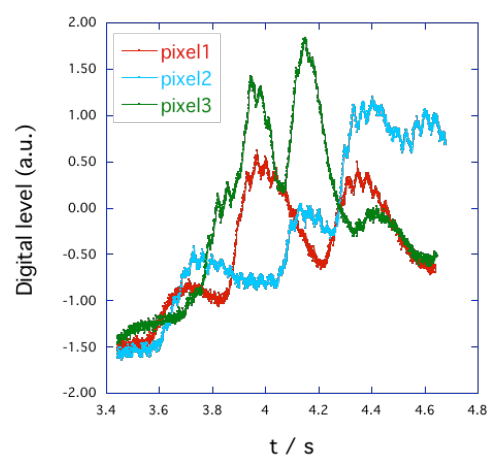

Fig. 2: Temperature (digital level) at chosen three pixels in different onionskin cells in cooling a, the magnified plot in $\boldsymbol{b}$.

\section{REFERENCES}

[1] Morikawa J. Hashimoto T. Hayakawa E. Uemura H. Two-dimensional thermal analysis for freezing of plant and animal cells by high-speed microscopic IR camera. In: Proceedings of SPIE 5073, Thermosense XXV, 2003 April 1 http://dx.doi.org/10.1117/12.487047.

[2] Hashimoto T, Morikawa J. Two-dimensional thermal analysis on freezing of onion epidermal cell by highspeed infrared microscopic camera. Jpn. J. Appl. Phys. Part B: Eng. 2003;42:L706.

[3] Pradere C. Morikawa J. Batsale J. C. Hashimoto T. Microscale thermography of freezing biological cells in view of cryopreservation. Quantitative Infra Red Thermography Journal 2009;6:37

[4] Morikawa J. Hayakawa J. Hashimoto T. Two-dimensional Thermal Analysis of Organic and Polymeric Materials with cooled and uncooled infrared cameras. Advances in Optical Technologies 2012; 2012:484650. 